\title{
Television and Fertility
}

\author{
STUART BASTEN, Ph.D., Research Scholar \\ International Institute for Applied Systems Analysis, IIASA Laxenburg, \\ Austria
}

\begin{abstract}
Much research has been conducted in the field of utilising the media - television and radio in particular - to promote particular public health messages. However, a burgeoning canon has examined how mass media can play a role in affecting change in fertility preferences and outcomes. In this paper we review these researches which have primarily focussed upon higher fertility settings. The impact of mass media presentation of families and children in low fertility settings has not yet been subject to rigorous sociological investigation so its impact can not be accurately inferred. However, given the pervasive nature of mass media and celebrity culture, we suggest that this is an important avenue for future research. We conclude that television plays a multi-faceted role in shaping individual's decision-making procedures concerning both demographic events and public health interactions. To illustrate this, we present a model which demonstrates a 'sliding scale' of intent - but not impact - of various genres in order to understand the actual role of the media in shaping attitudes towards family size - either explicitly in terms of 'edutainment' or implicitly as a forms of normalization.
\end{abstract}

Keywords: mass media, television, public health, fertility, family size

\section{Introduction}

The impact of media campaigns as public health interventions has been widely discussed and the potential benefits elucidated in many studies. In recent years, a growing number of studies have paid greater attention to the presentation of particular family formations as being a potential factor in shaping the fertility preferences of parents in the developing world. In the developed world, where low fertility prevails, the role of the media has often been discussed in terms of shaping attitudes towards family size (Lutz, Skirbekk et al. 2006), but has not been rigourously tested or theorised.

In this review, I present an introduction to the studies which have been produced, mainly from developing countries, which suggest a possible link between the presentation of certain family types and fertility intentions and actualisation. I shall then explore how the media can interact with decision-making in the developed world. 
By collecting these studies together, I am able to formulate a theoretical framework which suggests a 'sliding scale' of intent with regard to the perceived outcome of programme makers. Despite this, it is clear that the state of our knowledge concerning the two-way interaction between populaiton and media is, at least in reference to demographic behaviour, quite parlous.

\section{Media interventions}

\section{Media and public health}

Mass media interventions have been successful in changing and nurturing both public health activities and social and cultural norms. Family planning and reproductive health are two areas which have been widely used in mass media messaging for some time, particularly in the developing world (for a selective history of the role of Population Communications International, a leading advisor on this subject, see (Ryerson 1994)). Examples of successful interventions include the promotion of vasectomies in Brazil, Africa and Guatemala (Piotrow and Kincaid 1988; Kincaid, Merritt et al. 1996; Dunmoye, Moodley et al. 2001; Penteado, Cabral et al. 2001), encouraging HIV prevention and testing (Anon 2006; Rahman and Rahman 2007; Chandra, Jamaluddin et al. 2008; Marum, Morgan et al. 2008; Muula 2008) and the broader prevention of STIs (Kim and Marangwanda 1997; Jato, Simbakalia et al. 1999; Babalola and Vonrasek 2005; Bertrand and Anhang 2006). For example, Aga and van Rossem's (2002) survey of female condom use from the reactions of 2,712 sexually experienced men and women in Tanzania found that while only $6 \%$ of respondents had been exposed to either peer education or an explanation on use by a health provider, a full $38 \%$ of respondents had been exposed to some form of mass media campaign encouraging female condom use. As such, they found that 'mass media exposure significantly increased the likelihood that a man or a woman would discuss use of the female condom with a partner...In turn, discussion of the female condom with a partner strongly influenced the intention to use the female condom in the future' (p.156).

Of course, closely linked to the prevention of STIs via contraceptive use, is the promotion of family planning. In Nigeria, for example, a campaign using music videos produced by popular national artists promoting family planning began in 1989-90 was, after cross-sectional analysis, found to have had a significant effect on contraceptive use and intention as well as lowering desired family size (Bankole 1994; Bankole, Rodriguez et al. 1996). Meanwhile, the presentation of family planning themed skits in the country between 1985 and 1988 was followed by a dramatic (200-500\%) rise in new clinic clients in three regions (Piotrow, Rimon Ii et al. 1990). Elsewhere, mass media campaigns promoting family planning have proved successful in places as far afield as Mexico (Vernon 1978), Zimbabwe (Adamchak and Mbizvo 1991), Nepal (Boulay, Storey et al. 2002; Barber and Axinn 2004), Uganda (Gupta, Katende et al. 
2003), Ghana (Hindin, Kincaid et al. 1994), Bangladesh (Lieberman 1972; Kabir and Amirul Islam 2000; Mazharul Islam and Saidul Hasan 2000), Iran (Lieberman 1972), and India (Apte 1988; Kulkarni 2003). In Nepal, for example, Barber and Axinn (2004) found a relationship between exposure to mass media and preferences for smaller families, weaker son preference, and tolerance of contraceptive use. However, success in contraceptive and family planning promotion are not always so closely intertwined. In Ghana, for example, Parr $(2001,2002)$ found that while exposure to family planning messages via the radio and printed sources substantially increased use of modern contraception, exposure to family planning messages did not appear to have significant effects on fertility.

\section{Soap Operas in developing countries and the Sabido method}

While the interventions discussed above have tended to resemble advertisements, musical pieces, short skits or what might be termed public information broadcasts, one particular genre has been exploited as a very successful means of 'edutainment.' Soap operas, 'serial narratives,' or telenovelas in Latin and South America can either explicitly, or implicitly, convey a particular theme which can possibly influence viewers' behaviour. ${ }^{1}$ The theoretical underpinning of this has been partially developed in recent years (Dutta-Bergman 2006), with some even arguing that the format has the power to change and entrench (inherited) cultural norms (Fung 2007). Practically, a wide variety of messages - again both explicit and implicit - have been conveyed by soap operas with various effects. Soul City, for example, is a highly popular soap opera aired in southern Africa (part-funded by the UK government) which tackles a range of social issues from HIV and AIDS to rape (Peltzer and Promtussananon 2003; Goldstein, Usdin et al. 2005; Usdin, Scheepers et al. 2005; Cassidy 2008). Similarly in Egypt, Family House addressed issues such as AIDS, acute respiratory infections, home accidents, drug addiction, child marriages and spacing of births (Elkamel 1998).

Some soap operas are designed explicitly as a vehicle for the conveyance of a family planning message. Probably the most famous examples of these soaps can be found in Mexico. The first telenovela to promote family planning was a nine-month series entitled Acompañame (tr. 'Accompany Me') which was showed primetime, weekdays during 1977-78. The broad plotline is reproduced below:

Once upon a time Amanda, Raquel, and Esperanza were three happy-going young women growing up in Tacubaya. However, the three sisters' lives have become very different since marrying and forming their own families. Amanda is a middle class professional. She's had three children, all planned, and has raised them in a harmonious atmosphere. However, her happy family will soon be shattered when she learns her husband has terminal cancer. Raquel is a spoiled rich woman who

1 Telenovelas differ from European or Western soap operas in that they tend to run for 8-12 weeks as a whole with a resolving set of storylines, rather than the ongoing format of soaps such as EastEnders, Coronation Street, Neighbours or Melrose Place. 
only has one son. She's refused to give her husband more children in fear that they will destroy her body. Her only child grows unloved and neglected. Esperanza originally married a promising young man, but because she did not believe in contraceptives her family grew too large for comfort. Because her husband's salary is not enough to support them, Esperanza and her children, several of whom are psychotic and potential criminals, must move into a rundown shack where they cohabit in squalor and constant bickering (Series-Now 2009).

As a result of the series, a report commissioned by the Mexican Institute for Communication Research in 1981 found that

a) Phone calls to Mexico's national family planning office requesting family planning information increased from zero to an average of $500 \mathrm{a}$ month. Many people calling mentioned that they were encouraged to do so by the television soap opera.

b) More than 2,000 women registered as voluntary workers in the National Program of Family Planning. This was an idea suggested in the television soap opera.

c) Contraceptive sales increased 23 percent in one year, compared to a seven percent increase the preceding year.

d) More than 560,000 women enrolled in family planning clinics, an increase of 33 percent (compared to a one percent decrease the previous year) (PMC 2009).

As a result of the success of Acompañame, Mexican TV network Televisa commissioned four more family planning soaps which ran throughout the 1970s and 1980s Vamos Juntos (We Go Together), Caminemos (Let's Walk), Nosotros las Mujeres (We the Women), and Por Amor (For Love) - during which period Mexico's population growth rate declined by $34 \% .{ }^{2}$ Indeed, Thomas Donnelly, of the United States Agency for International Development (USAID) in Mexico until 1983 stated that 'Throughout Mexico, wherever one travels, when people are asked where they heard about family planning, or what made them decide to practice family planning, the response is universally attributed to one of the soap operas that Televisa has done...The Televisa family planning soap operas have made the single most powerful contribution to the Mexican population success story' (PMC 2009).

Soap operas with an explicit family planning message can be found elsewhere. Apwe Plezi, a radio soap opera in St. Lucia has, for example, 'influenced listeners to increase their awareness of contraceptives, improve important attitudes about fidelity and family relations, and adopt family planning techniques' (Vaughan, Regis et al. 2000, p.148). Similarly in Tanzania, a radio soap opera entitled Twende na Wakati (tr. 'Let's Go with

2 All of these shows, as well as Acompañame, were produced by Miguel Sabido, after whom the 'Sabido Methodology' of pro-social serial programming has been coined (PMC 2009). 
the Times') was deemed to have had 'strong behavioural effects on family planning adoption; it increased listeners' self-efficacy regarding family planning adoption and influenced listeners to talk with their spouses and peers about contraception' (Rogers, Vaughan et al. 1999, p.193).

In India, the first 'social soap opera', Hum Log (tr. 'People Like Us'), which began broadcasting in 1984, averaged an audience of 50 million people (CIN 2009). Set amongst lower middle-class joint family, the serial had promoted equal status for women, family harmony, and smaller family size norms. Epilogues were used at the end of each programme which related the content of the programme to viewer's daily lives. The epilogues were delivered by a famous Hindi actor, Ashok Kumar, and ended with an address to which letters regarding the programme could be directed (CIN 2009). The relationship between characters storylines and the lives of the viewers were often strong. Indeed, 'viewers sent more than 400,000 letters, many of them addressed to the characters rather than to the actors and actresses...Many of these viewers identified with one or more of the characters, and many commented on the social issues raised by the show' (Chatterji 2008). A survey of 500 such letters written found that ' $92 \%$ were influenced in a pro-social direction, $7 \%$ showed behavioural change as a result of the show. For example, there was an increase in the number of people signing up to give eye donations, due to a story line where the grandmother had eye cancer' (CIN 2009). Furthermore, ' $53 \%$ of respondents believed in copying positive role models identified in Hum Log, 23\% believed in copying negative role models. $70 \%$ believed that women should have equal opportunities, $71 \%$ said that family size should be limited, $64 \%$ thought women's welfare programs should be encouraged...33\% of the sample of 500 letters had their social attitudes influenced by the show' (CIN 2009).

Hum Log was, however, distinct from its Mexican forbears inasmuch as there was 'a lack of formative research as well as no development of interinstitutional coordination among media, public health agencies, voluntary groups, and other organisations' and that "the initial programmes used a "hard sell" approach to communicating the family planning messages, which was also inconsistent with the Sabido methodology' (CIN 2009). Indeed, Chaterji (2009) has suggested that - at least looking back from the 2000 s - the show presented clumsy and ambiguous messages regarding the emancipation of women. For example, 'in keeping with Gandhian ideology, the women took up jobs or pursued careers, but such jobs were not in conflict with their wife-motherdaughter role within the family...Kamya, the spoilt daughter of a millionaire who the youngest son fell in love with, was the only woman who had the guts to leave her debauch husband. Yet, despite her education and modern upbringing, she was gullible to the point of being stupid' (Chatterji 2008). Furthermore, while a large proportion of viewers may have been affected, or were made to 'think' about the issues raised, ultimately only $7 \%$ of the survey respondents actually changed their behaviour as a result' (Chatterji 2008). 


\section{Brazilian telenovelas}

Along with Mexico, telenovelas in Brazil have been studied intensively in terms of their relation to family planning and fertility rates. Within three decades, exposure to television coverage rose from zero to become almost universal in urban areas and to almost half in rural households. Coterminous with this rise in telenovelas is a dramatic drop in fertility rates - as evidenced in figure 2 below - from over 6 in 1960 to below 2 today (IBGE 2004; Kent 2009). A further important feature of Brazilian telenovelas is that, as Dunn observes, 'while in many parts of the world television viewing decreases with increased educational attainment, in Brazil the reverse is true' (p.9).

As well as a generally better quality of script and production, the fundamental difference between the Brazilian telenovelas, and those which follow (or broadly follow) the Sabido methodology, is that family planning and population control is not explicitly addressed in the Brazilian variants. Indeed, the advertising of contraceptive methods was illegal in Brazil until the late 1970s. Instead, they were vehicles for writers 'employ...the cultural industry as a way to fight dictatorship through the reinforcement of new values and ideas in their plots' (La Ferrara, Chong et al. 2008, p.8). As such, recurring themes included 'freedom, criticism of religious and traditional values, consumption of luxurious goods, the portrayal of wealthy families, the display of new lifestyle, the circulation of modern ideas such as female emancipation in the work sphere, the female pursuit of pleasure and love even if through adultery, displays of homosexuality, criticism of machismo and emphasis on individualism' (ibid.; see also Rios-Neto, Miranda-Rebeiro et al. 1998; Hamburger 2001; Rios-Neto 2001). As La Ferrara et al. (2008, p.8) state, 'telenovelas were, and still are, loaded with, material directly or indirectly relevant to family size preferences'. Indeed, a content analysis of 115 telenovelas between 1965 and 1999 - highlighted in figure 3 below - reveals that $72 \%$ of the main female characters (aged $<50$ ) had no children at all, while $21 \%$ had only one - all, of course, in marked contrast to prevalent fertility rates in Brazil during this period. In other words, 'Television reiterates the disclosure of a very specific model of family: small, beautiful, white, healthy, urban, middle and upper class consumerist family... Novelas have been a powerful medium through which the small family has been idealized' (ibid.)

The influence of telenovelas on everday life is often profound. Specific language presented in the telenovelas has been seen re-enacted among viewers, while in northeastern Brazil, 'local residents referred to novela characters and storylines in everyday conversations, using the (often exaggerated) faults of novela characters to describe the misdeed or character flaws of relatives or others in the community' (Dunn 2001, p.31). Furthermore, the chances of a new-born baby being named after a soap star were significantly higher in areas where the soaps were broadcast (Downie 2009). 
Figure 1. Average number of children of main female character in telenovelas, by year (La Ferrara, Chong et al. 2008).

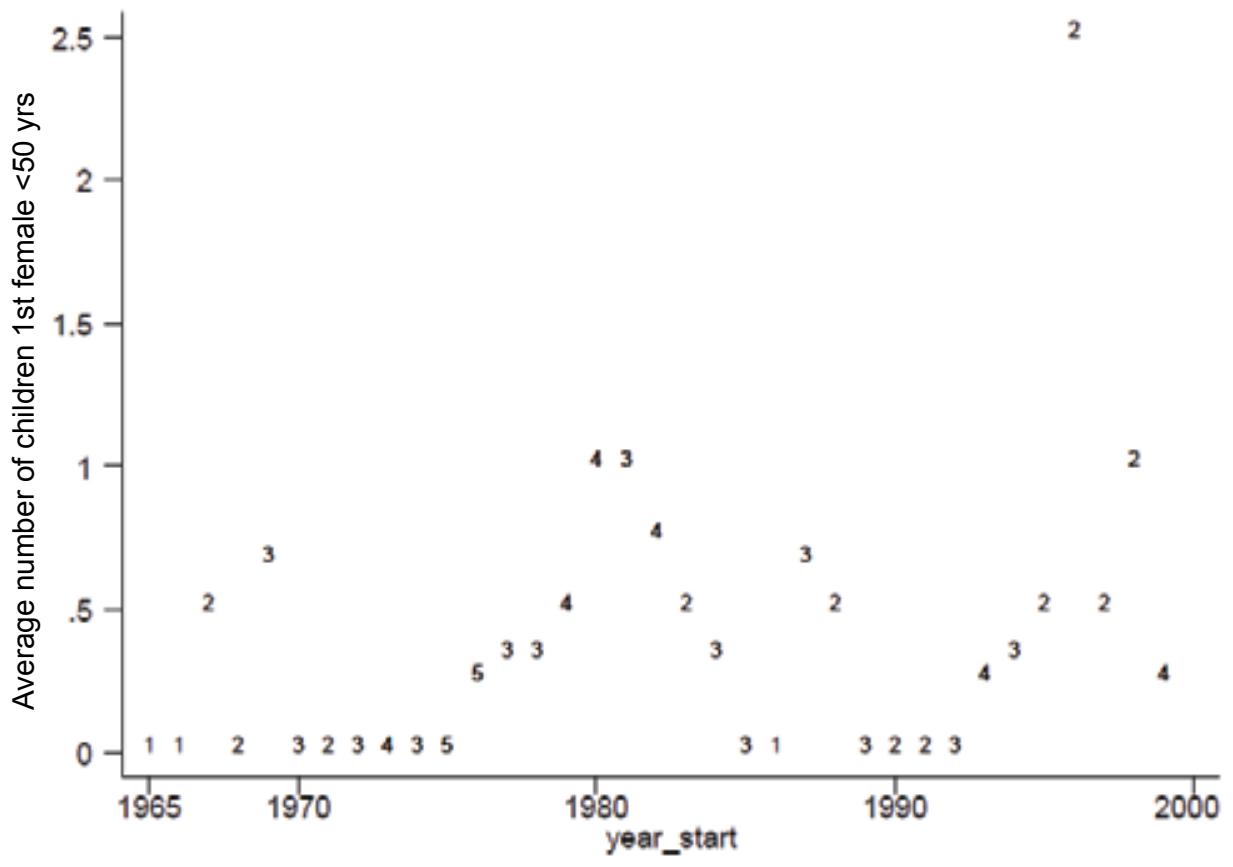

Note: Numbers on each data point indicate the number of novelas from which the average is computed.

It is not, of course, particularly wise to make a direct link between the growth of the telenovela and falling fertility rates. In Dunn's study of north-eastern Brazil, 'none of the women in the study suggested that television or radio had changed their own individual reproductive behaviours or their attitudes about family size and family planning'. However, with desired family size tumbling to 2 or fewer, particularly within a context of difficult economic circumstances, Dunn (2001, p.35) believes the media has played a role: 'through a variety of programs - including news broadcasts that focus on the state of the economy and the plight of low-skilled and poorly educated workers, and novela images of middle-class urban families who enjoy comfortable lives and who lavish their children with consumer goods and purchased services - the electronic media project potent images of an urban lifestyle that depends on wage labour, yet is rife with uncertainty'.

La Ferrara et al. (2008) sought to test more robustly the hypothesis that 'constant exposure to smaller, less burdened television families, may have created a preference for fewer children and greater sensitivity to the opportunity costs of raising children'. This analysis is achieved by exploiting the differences in the timing of entry into different markets by Rede Globo, the television network which, until the early 1990s, had an effective monopoly on telenovela production in Brazil. The headline finding is that 'after controlling for time varying controls and for time-invariant area characteristics, 
the presence of the Globo signal leads to significantly lower fertility.' This effect appear to be heightened among women of a lower socioeconomic status, and among women who are in the middle or late phases of their childbearing careers, suggesting television contributed more to stopping rather than postponing behaviour - a feature consistent with available demographic data for Brazil (La Ferrara, Chong et al. 2008). Indeed, a similar effect was found among divorce rates, which also rose when the Globo signal was received in a given area (Chong and La Ferrara 2009).

Finally, a recent study has revisited the Indian context to examine in greater detail the impact of the introduction of cable television on local communities (Jensen and Oster 2009). Recent Indian television output has heavily featured soap operas, such as Kyunki Saas Bhi Kabhi Bahu Thi (Because a Mother-in-Law Was Once a Daughter-in-Law, Also), which, like the Brazilian telenovelas, are overwhelmingly set in urban locations. As such, for the many rural viewers, a different society is being regularly presented and where women are typically presented to be much more emancipated. Jensen and Oster's (2009) analysis found an association between 'the introduction of cable television with significant decreases in the reported acceptability of domestic violence towards women and son preference, as well as increases in women's autonomy, decreases in fertility and suggestive evidence for increased school enrollment for the young owing to greater female influence in household decision making. This provides some quantitative evidence to confirm anthropological reports describing the perceived effect of introducing television on gender empowerment in India (Johnson 2001; Scrase 2002).

\section{A role for television in population policy in the developing world?}

As television becomes more ubiquitous in the developing world, mass media messages may develop as an increasingly important component of public health, family planning and general development policies. These messages can - and have - been 'blended' to include both a presentation of a potential 'better life' through aspiration to education and gender empowerment and a sense of heightening the urgency of particular public health initiatives. In other words, such messages are able to balance the top-down imperatives of safe sex and HIV-AIDS prevention with the post-Cairo population consensus of reproductive rights. A major caveat to this, however, is that the rapid growth of the Internet has the potential to supersede television as 'first point of contact' for entertainment. However, given the extremely low levels of Internet access penetration in Africa, this is unlikely in the short term. (Internet World Stats 2009). A further caveat can be drawn from evidence gathered in Indonesian villages by Olken (2006), who finds that increased media access and more time spent watching television and listening to the radio, 'is associated with substantially lower levels of participation in social organizations and with lower self-reported measures of trust' with particularly negative effects on participation in both local government activities and informal savings groups. This negative effect on social capital, therefore, presents just one piece of evidence that television is not quite the 'silver bullet' we might hope for. 


\section{Media and the family in low fertility countries}

The evidence above suggests that television can play an important, if often indirect role, in what might be termed the decision-making process of both families and individuals concerning certain demographically measurable activities such as family planning, public health and fertility. But can this be translated to low fertility settings?

The theoretical presence for a role for television within the demographic canon can be found in the so-called 'Low Fertility Trap Hypothesis', which posits that in a setting of falling fertility rates, a process of normalisation and socialisation occurs with smaller families not only being commonplace among friends, siblings and colleagues, but also in representation in the media. Once fertility falls below a certain level, and in the context of this cultural normalisation, 'ideal family size would become lower, which in course may result in further declining actual family size and still lower ideals in the subsequent generation' (Lutz, Skirbekk et al. 2006, p.18). ${ }^{3}$

In this vein, it is important to understand how mass media in the developed world reflects and presents the family in its broadest sense in low fertility countries. Some work has approached this in terms of the presentation of childlessness and 'ideal families' on television, but the research in this area is very much underdeveloped. ${ }^{4}$ As Goldstein et al. (2003, p. 491) observe, anecdotal evidence suggests that 'large families are not a feature of German or Austrian television (except through American imports)' - implying that the USA's higher fertility rates are reflected in its' media output (Goldstein, Lutz et al. 2003). However, it is not as clear cut as this might suggest. For example, the genres in which families are presented in various forms are immense. These include animated presentations of dysfunctional families - The Simpsons, American Dad, Family Guy, South Park; reality shows featuring celebrity families - The Osbournes, Hammertime, Keeping Up With The Kardasians and the presentation of perpetually single adults in Friends and Sex in the City. As yet, a full content analysis of the changing presentation of family size, family typologies and attitudes towards children has not yet been performed. This is surely an important research priority.

While television and fertility has not yet been fully considered for developed countries, a number of studies have been carried out which consider the public health implications of the presentation of certain illnesses. In Britain, for example, the recent high profile death of a young celebrity (Jade Goody) of cervical cancer has caused a spike in the number of tests carried out (Cassidy 2009; South Wales Evening Post 2009). Furthermore, a storyline in the long running ITV soap opera Coronation Street where

3 Indeed, there are also occasions where society can change to leave television behind. Consider the British soap operas EastEnders and Coronation Street, which follows the families of two areas of urban London and Manchester. In both of these serial dramas, there is a deep interaction between neighbours on a social, economic, and romantic level. However, this in fact bears little relation to contemporary urban Britain.

4 For an exception, see (Sass 2004). 
one of the characters died from cervical cancer had a similar effect in 2000-01, where 'the number of smears performed increased from 65714 in 2000 to 79712 in 2001', an increase of over 20 per cent in the months after the story was broadcast (Howe, Owen-Smith et al. 2002, p.299). Other behaviours observed in British soap operas are discussed by Verma et al. (2007), who conclude that "popular television serials offer the chance to portray "healthy" behaviours as normal, and so help change attitudes and shape behavioural norms among the viewing public'. As such, 'engaging the makers of these programmes in a health promotion agenda may be a fruitful method of promoting healthy behaviours' (p.577)

\section{Theorising television and demographic behaviour}

We present a hypothetical model in Figure 2 based upon our a priori expectations. Our model suggests three 'stages of intent' ranging from the explicit public health and family planning messages of government- or NGO-led initiatives, through the telenovelas and soap operas of Brazil and India which, while not promoting a given way of life, presented small, rich, urban, more equal families to an audience hitherto without experience of - or interaction with - such family forms. It might be more useful to think of these genres in terms of how the creators intend an interaction with the audience. These range from a 'top-down' message, through an implicit recommendation, sometimes aimed at creating a new cultural paradigm outside the sphere of explicit government control (although this might be disputed by Brazilian and Indian TV channels). However, both of these approaches leave us somewhat puzzled when we reach low fertility countries. In some ways, this reaches into the very heart of just what the media, especially in the West, does in terms of reflecting real or skewed (sometimes to an extreme degree) the characteristics of its audience, and the possible feedback effect that that might have. 
Figure 2. A hypothetical model of the interaction between mass media (television) and demography.

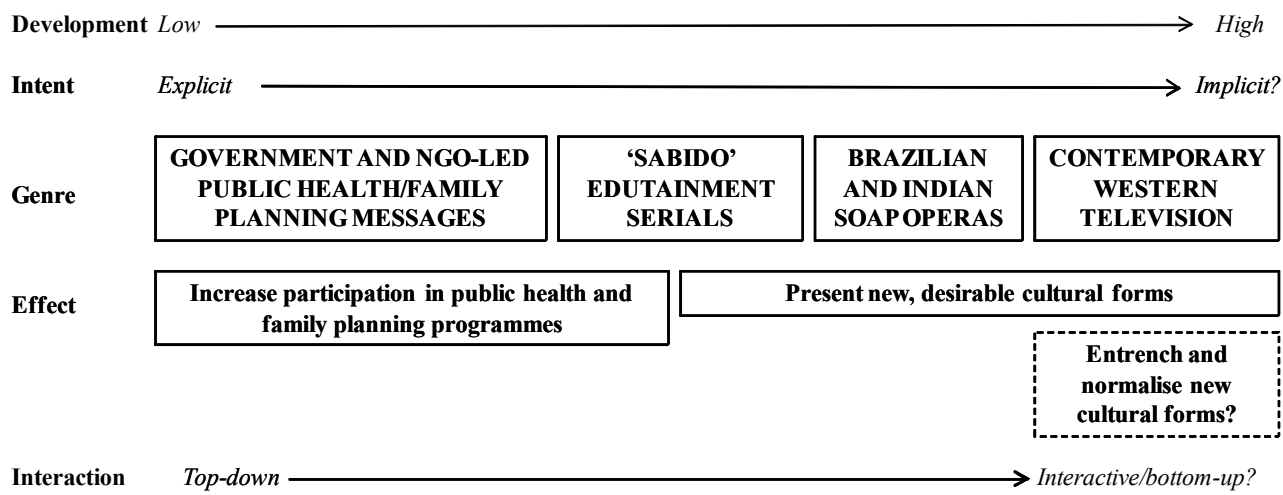

\section{Conclusion}

The evidence presented in this paper emanates primarily from higher fertility countries and suggests that television could play a role, albeit indirectly, in attitudes toward family size. However, we know very little about the role of television - and by extension advertising and celebrity culture - in individual formation of ideas concerning childbearing.

It is vital, therefore, to foster a greater relationship between demography and the television and media industries, in conjunction with areas such as advertising, psychology and sociology to gain a greater understanding of the possible interactions between the various presentations of family life on television, and views held by, particularly, young people. Only by pursuing this research agenda will we be able to fully understand the role, and significance, of the media as a component of the Low Fertility Trap Hypothesis and other theories of low fertility societies. Indeed, as other studies begin to probe the impact of both explicit and implicit media message on other walks of life such as voting behaviour (DellaVigna and Kaplan 2007; Ho and Quinn 2008; Ladd and Lenz 2009), consumption (Chavis and Leslie 2009), eating disorders (Becker 2004), and women's rights and sex stereotypes (Morgan and Rothschild 1983; Holbert, Shah et al. 2003) an analysis of this kind would be timely. In the words of Hornik and MacAnany's $(2001,47)$ appeal for further research, 'such examinations of further evidence will help sort through the complex process of media influence on a broader scale and help both theory building and policy development for the media's more beneficial applications for social change'. 


\section{Bibliography}

Adamchak, D. J. and M. T. Mbizvo. 1991. Family planning information sources and media exposure among Zimbabwean men. Studies in Family Planning 22(5): 326-331.

Agha, S. and R. Van Rossem. 2002. Impact of mass media campaigns on intentions to use the female condom in Tanzania. International Family Planning Perspectives 28(3): 151-158.

Anon. 2006. Media crucial to AIDS fight. AIDS patient care and STDs 20(9): 662.

Apte, J. M. 1988. A study of relationship between background characteristics, media exposure and acceptance of family planning in rural Maharashtra. IIPS newsletter 29(4): 13-22.

Babalola, S. and C. Vonrasek. 2005. Communication, ideation and contraceptive use in Burkina Faso: an application of the propensity score matching method. Journal of Family Planning and Reproductive Health Care 31(3): 207-212.

Bankole, A. 1994. The role of mass media in family planning promotion in Nigeria. DHS Working Paper 11.

Bankole, A., G. Rodriguez, et al. 1996. Mass media messages and reproductive behaviour in Nigeria. Journal of biosocial science 28(2): 227-239.

Barber, J. S. and W. G. Axinn. 2004. New ideas and fertility limitation: the role of mass media. Journal of marriage and family 66(5): 1180-1200.

Becker, A. E. 2004. Television, disordered eating, and young women in Fiji: negotiating body image and identity during rapid social change. Culture, Medicine and Psychiatry 28(4): 533-559.

Bertrand, J. T. and R. Anhang. 2006. The effectiveness of mass media in changing HIV/AIDS-related behaviour among young people in developing countries. World Health Organization - Technical Report Series: 205-241.

Bielby, D. D. and C. L. Harrington. 2005. Opening America? The telenovela-ization of U.S. soap operas. Television \& New Media 6(4): 383-399.

Boulay, M., J. D. Storey, et al. 2002. Indirect exposure to a family planning mass media campaign in Nepal. Journal of Health Communication 7(5): 379-399.

Cassidy, J. 2008. The soap opera that saves lives. BMJ 336(7653): 1102-1103.

--- 2009. Jade, class, and cervical cancer. $B M J$ 2009, 338:b691

Chandra, H., K. Jamaluddin, et al. (2008). HIV/AIDS awareness through mass media-the measurement of efforts made in an urban area of India. Indian journal of public health 52(3): 171-172.

Chatterji, S. 2008. India together: looking back at hum log. [cited 27 May 2009]. Available from: http://www.indiatogether.org/2008/jul/wom-humlog.htm.

Chavis, L. and P. Leslie. 2009. Consumer boycotts: the impact of the Iraq war on french wine sales in the U.S. Quantitative Marketing and Economics 7(1): 37-67.

Chong, A. and E. La Ferrara. 2009. Television and divorce: evidence from Brazilian novelas. Journal of the European Economic Association 7(2-3): 458-468.

CIN. 2009, 29th April 2009. Hum log. [cited 27 May 2009]. Available from http:// www.comminit.com/en/node/2220/print.

DellaVigna, S. and E. Kaplan. 2007. The fox news effect: media bias and voting. Quarterly Journal of Economics 122(3): 1187-1234. 
Downie, A. 2009. Brazil's racy telenovelas inspire drop in birth rate, rise in divorce. The Daily Telegraph UK. London.

Dunmoye, O. O., J. Moodley, et al. 2001. Vasectomy in developing countries. Journal of Obstetrics and Gynaecology 21(3): 295-297.

Dunn, J., S. 2001. Mass media and individual reproductive behavior in northeastern Brazil. Paper presented at the XXIV General Population Conference of the International Union for the Scientific Study of Population, Salvador, Brazil,

Dutta-Bergman, M. J. 2006. A formative approach to strategic message targeting through soap operas: using selective processing theories. Health Communication 19(1): 11-18.

Elkamel, F. M. 1998. Soap operas may be good for health: impact evaluation of the Egyption soap opera, 'Family House'. Eastern Meditteranean Health Journal 4(1): 178-180.

Fung, A. 2007. Intra-Asian cultural flow: cultural homologies in Hong Kong and Japanese television soap operas. Journal of Broadcasting and Electronic Media 51(2): 265-286.

Goldstein, J., W. Lutz, et al. 2003. The emergence of Sub-Replacement Family Size Ideals in Europe. Population Research and Policy Review 22(5): 479-496.

Goldstein, S., S. Usdin, et al. 2005. Communicating HIV and AIDS, what works? A report on the impact evaluation of Soul City's fourth series. Journal of Health Communication 10(5): 465-483.

Gupta, N., C. Katende, et al. 2003. Associations of mass media exposure with family planning attitudes and practices in Uganda. Studies in Family Planning 34(1): 19-31.

Hamburger, E. 2001. Telenovela,gender and demography in Brazil. Paper presented at the XXIV General Population Conference of the International Union for the Scientific Study of Population, Salvador, Brazil,

Hindin, M. J., D. L. Kincaid, et al. 1994. Gender differences in media exposure and action during a family planning campaign in Ghana. Health Communication 6(2): 117-135.

Ho, D. E. and K. M. Quinn. 2008. Measuring explicit political positions of media. Quarterly Journal of Political Science 3(4): 353-377.

Holbert, R. L., D. V. Shah, et al. 2003. Political implications of prime-time drama and sitcom use: genres of representation and opinions concerning women's rights. Journal of Communication 53(1): 45-60.

Hornik, R. and E. McAnany. 2001. Theories and evidence: mass media effects and fertility change. Communication Theory 11(4): 454-471.

Howe, A., V. Owen-Smith, et al. 2002. The impact of a television soap opera on the NHS Cervical Screening Programme in the North West of England. Journal of Public Health Medicine 24(4): 299-304.

IBGE (Instituto Brasileiro de Geografia e Estatística). 2004. Projecao da populacacao do Brasil por sexo e idade para o periİo de 1980-2050: revisao 2004.

Internet World Stats. 2009. Internet Usage Statistics for Africa. Available from: http:// www.internetworldstats.com/stats1.htm.

Jato, M. N., C. Simbakalia, et al. 1999. The Impact of multimedia family planning promotion on the contraceptive behavior of women in Tanzania. International Family Planning Perspectives 25(2): 60-67. 
Jensen, R. and E. Oster. 2009. The power of TV: cable television and women's status in India. Quarterly Journal of Economics 124(3): 1057-1094.

Johnson, K. 2001. Media and social change: the modernizing influences of television in rural India. Media, Culture and Society 23(2): 147-169.

Kabir, M. and M. Amirul Islam. 2000. The impact of mass media family planning programmes on current use of contraception in urban Bangladesh. Journal of biosocial science 32(3): 411-419.

Kent, M. M. 2009. Brazil's fertility falls below two-child average. Population Reference Bureau. [cited 28h May 2009]. Available from: http://www.prb.org/Articles/2009/ braziltfrdecline.aspx.

Kim, Y. M. and C. Marangwanda 1997. Stimulating men's support for long-term contraception: a campaign in Zimbabwe. Journal of Health Communication 2(4): 271-297.

Kincaid, D. L., A. P. Merritt, et al. 1996. Impact of a mass media vasectomy promotion campaign in Brazil. International Family Planning Perspectives 22(4): 169-175.

Kulkarni, M. S. 2003. Exposure to mass media and its impact on the use of family planning methods by women in Goa. Health and Population: Perspectives and Issues 26(2): 87-93.

La Ferrara, E., A. Chong, et al. 2008. Soap operas and fertility: Evidence from Brazil. Working Paper 172. Bureau for Research and Analysis of Development (BREAD), Duke University

Ladd, J. M. and G. S. Lenz. 2009. Exploiting a rare communication shift to document the persuasive power of the news media. American Journal of Political Science 53(2): 394-410.

Lieberman, S. S. 1972. Family planning in Iran: results of a survey and a mass media campaign. Iranian studies : bulletin of the Society for Iranian Cultural and Social Studies 5(4): 149-180.

Lutz, W., V. Skirbekk, et al. 2006. The low-fertility trap hypothesis: Forces that may lead to further postponement and fewer births in Europe. In: Vienna Yearbook of Population Research 2006, edited by..., pp.167-192.

Marum, E., G. Morgan, et al. 2008. Using mass media campaigns to promote voluntary counseling and HIV-testing services in Kenya. AIDS 22(15): 2019-2024.

Mazharul Islam, M. and A. H. M. Saidul Hasan. .(2000.). Mass media exposure and its impact on family planning in Bangladesh. Journal of biosocial science 32(4): 513-526.

Morgan, M. and N. Rothschild. 1983. Impact of the new television technology: cable $\mathrm{TV}$, peers, and sex-role cultivation in the electronic environment. Youth and Society 15(1): 33-50.

Muula, A. S. 2008 South Africa's national response to HIV and AIDS treatment: popular media's perspective. Croatian Medical Journal 49(1): 114-119.

Olken, B. 2006. Do television and radio destroy social capital? Evidence from Indonesian villages. NBER Working Paper: 125-161.

Parr, N. 2001. Mass media promotion of family planning and the use of modern contraception in Ghana. Presented at the 24th IUSSP General Conference, Salvador, 
Brazil,

Parr, N. 2002. Family planning promotion, contraceptive use and fertility decline in Ghana. African Population Studies 17: 83-101.

Peltzer, K. and S. Promtussananon. 2003. Evaluation of soul city school and mass media life skills education among junior secondary school learners in south africa. Social Behavior and Personality 31(8): 825-834.

Penteado, L. G., F. Cabral, et al. 2001. Organizing a public-sector vasectomy program in Brazil. Studies in Family Planning 32(4): 315-328.

Piotrow, P. T. and D. L. Kincaid. 1988. How should vasectomy be promoted in Guatemala? Studies in Family Planning 19(4): 248-249.

Piotrow, P. T., J. G. Rimon Ii, et al. 1990. Mass media family planning promotion in three Nigerian cities. Studies in Family Planning 21(5): 265-274.

PMC. 2009. Sabido Methodology. [cited 24 May 2009]. Available from: http://www. populationmedia.org/what/sabido-method/.

Rahman, M. S. and M. L. Rahman. 2007. Media and education play a tremendous role in mounting AIDS awareness among married couples in Bangladesh. AIDS Research and Therapy 4.

Rios-Neto, E. 2001. Television, value constructs, and reproductive behaviour in Brazilian 'excluded communities. Presented at the IUSSP XXIV General Population Conference,

Rios-Neto, E. P., P. Miranda-Rebeiro, et al. 1998. I saw it on TV: Television and demographic change in Brazil. Paper presented at the Workshop on the Social Dynamics of Fertility Change in Developing Countries,

Rogers, E. M., P. W. Vaughan, et al. 1999. Effects of an entertainment-education radio soap opera on family planning behavior in Tanzania. Studies in Family Planning 30(3): 193-211.

Ryerson, W. N. 1994. Population communications international: its role in family planning soap operas. Population and Environment 15(4): 255-264.

Sass, E. 2004. Reconstructing the image of the voluntarily childfree: an ethnographic exploration of media representation and the childless by choice. MA: 111. School of Mass Communications, University of South Florida.

Scrase, T. J. 2002. Television, the middle classes and the transformation of cultural identities in West Bengal, India. Gazette 64(4): 323-342.

Series-Now. 2009. Acompaname. [cited 27 May 2009]. Available from: http://www. seriesnow.com/mexican-telenovelas/acompaname.html.

South Wales Evening Post 2009. Jade Goody's death sparks record number of smear tests. [cited May 29 2009]. Available from: http://www.thisissouthwales.co.uk/news/JadeGoody-s-death-sparks-record-number-smear-tests/article-980798-detail/article.html.

Usdin, S., E. Scheepers, et al. 2005. Achieving social change on gender-based violence: a report on the impact evaluation of Soul City's fourth series. Social Science and Medicine 61(11): 2434-2445.

Vaughan, P. W., A. Regis, et al. 2000. Effects of an entertainment-education radio soap opera on family planning and HIV prevention in St. Lucia. International Family Planning Perspectives 26(1): 148-157. 
Vaughan, P. W. and E. M. Rogers. 2000. A staged model of communication effects: evidence from an entertainment-education radio soap opera in Tanzania. Journal of Health Communication 5(3): 203-227.

Verma, T., J. Adams, et al. 2007. Portrayal of health-related behaviours in popular UK television soap operas. Journal of Epidemiology and Community Health 61(7): 575-577.

Vernon, R. 1978. Mexico's first mass media campaign for family planning. Family planning resume 2(1): 82-84. 